\title{
Sustainable Innovation and Creativity for Value Creation: A Study of Hospitality Enterprises in Jos Metropolis, Nigeria
}

\author{
Danjuma T. Nimfa \\ Putra Business School, University Putra Malaysia \\ Mohd Rashid Bin Mohd Yunus \\ Putra Business School, University Putra Malaysia \\ Ahmad S. A. Latiff, (PhD) \\ Putra Business School, University Putra Malaysia \\ Sazali A. Wahab (PhD) \\ Putra Business School, University Putra Malaysia \\ Rosli Mahmood (PhD) \\ Putra Business School, University Putra Malaysia
}

\begin{abstract}
Hospitality enterprises in Nigeria are currently experiencing serious stagnation. Their rate of value creation has been on the decline as a result of inadequate sustainable innovation, creative skills, emerging technology, and inadequate adoption of the automation system. This study aims to investigate the impacts of sustainable innovation on creativity for the creation of value in hospitality enterprises in Jos Metropolis. 108 individuals were selected as the sample size through the formula by Morgan and Krejcie. Furthermore, a quantitative approach was applied as the primary method of data collection. The formulated hypotheses were tested using Ordinary Least Squares (OLS) regression method. Based on this study's findings, a significant association was proven between sustainable innovation and customers' satisfaction, creativity skills, and competitiveness. However, there was no significant association between the utilisation of technology and the creation of value in hospitality enterprises. Lastly, it is recommended that owner-managers in hospitality enterprises improve their sustainable innovation for value creation and service delivery. They should focus on customers' needs and satisfaction, the utilisation of technology, in the long run, improvement in the return on investment, increase in profit margins and revenue, and large market share for sustainable growth of the hospitality enterprises in Jos Metropolis.
\end{abstract}

Keywords: Sustainable innovation, Creativity, Value creation, Hospitality enterprises, Jos, Metropolis

DOI: $10.7176 / \mathrm{EJBM} / 11-26-04$

Publication date:September $30^{\text {th }} 2019$

\subsection{INTRODUCTION}

There has been a significant increase in the sustainability of the hospitality industry over the past few years compared to its usual state. However, this industry makes a significantly small contribution to sustainability in society's development (Melissen \& Sauer, 2019). Currently, hospitality enterprises in Nigeria are experiencing serious stagnation. Furthermore, their rate of value creation has been on the decline as a result of inadequate sustainable innovation, creative skills, emerging technology, and inadequate adoption of the automation system. This crisis was also due to high global competition, economic recession, and the increase in activities of insurgency, including material and energy costs. The importance of sustainable innovation and creativity in hospitality enterprise is constantly emphasised due to the concepts applied in understanding the driving forces of value creation. Moreover, the impacts of management innovation at the functional and organisational level (e.g. employee ambidexterity, involvement, and ability, organisational commitment, operational and financial organisation's performance) should be highlighted more often compared to those at the individual level (e.g. agility, creativity, objective, and health) (Millar, Groth \& Mahon, 2018).

SMEs need to enhance their innovation capabilities (Halim, Ahmad, Ramayah \& Hanifah, 2014). Notable instances of virtual studies could be seen from previous works of literature by Dedeoğlu, Aydın and Boğan, (2018) and Dzhandzhugazova, Blinova, Orlova and Romanova (2016). The term innovation is within the scope of the commercialisation of emerging ideas. In a simpler term by this study, innovation is identified as ideas which have been completely commercialised and original ideas which are meant for commercialisation in the market (Dziallas \& Blind, 2019). Trendy business practices have had to evolve at a fast rate in order to remain effective. As the large-scale business has historically accounted for the bulk of revenue in developing economies, the out-sourcing of their production and market distribution would reduce the stability and growth of those economies. However, a switch in business opportunities through innovations may be needed for these transformations to achieve 
sustainability (Bocken, Short, Rana \& Evans 2014; Schaltegger \& Ludeke-Freund, 2012).

This switch should be visible by reconsidering value perspective and the development of new values (Stubbs \& Cocklin, 2008). However, developing an overview of the contribution of science is often a challenging task to be done by researchers and practitioners from various domains of knowledge. This is because the 'status quo' for the 'innovation for sustainability' is provided by the formalised categorisation of business model innovations (Bocken et al., 2014). Sustainability issues are incorporated into existing industrial processes. Additionally, the use of ontologies could be the alternatives to these models as they could be utilised as a tool for knowledge sharing in society (Rabino, Borri \& Stufano Melone, 2014).

Creativity enhances strategies for determining problems. This does not take into account the inclination to square measure the development of a brand new strategy. Creativity in this respect is also not associated with innovative thinking kept before the competition. Therefore, the collaboration of committed workforce, specific management and entrepreneurial skills, and climate and financial conditions which lead to an ideal state for success are essential for sustainable creativity and innovation. However, there are inadequate sensitisation initiatives, capacity, and awareness for the creation of value for customers in most hospitality enterprises.

There is inadequate attention given to highlight sustainable innovation and creativity for value creation in hospitality enterprises. Therefore, this study aims to investigate the influence of sustainable innovation and creativity for the value creation of hospitality enterprises in Jos Metropolis. The research questions in this study are as follows:

1. To what extent has sustainable innovation promoted customer's satisfaction in hospitality enterprises in Jos Metropolis?

2. How does creativity skill enhance competitiveness in hospitality enterprises in Jos Metropolis?

3. Has the utilisation of technology encouraged value creation for business opportunities in hospitality enterprises in Jos Metropolis?

This study mainly aims to examine the sustainable innovation of creativity for the value creation of hospitality enterprises in Jos Metropolis. It also aims to 1) examine whether sustainable innovation has promoted customer's satisfaction in hospitality enterprises in Jos Metropolis, 2) analyse how creativity skills enhance competitiveness in hospitality enterprises in Jos Metropolis, and 3) evaluate the utilisation of technology and value creation of hospitality enterprises in Jos Metropolis for business opportunities.

\subsection{Sustainable Innovation}

Sustainable innovation may be a strategy in a case when financial, social, and environmental property issues are incorporated into organisation systems. This incorporation ranges from the planning of generation to analysis and development (R\&D). In this phase, technologies, services, products, and new organisation models and businesses are involved (Katerva, 2019). There are various stakeholders for an organisation, namely governments, customers, employees, suppliers, communities, NGOs/activists, competitors, and many more. Therefore, innovation is essential for the organisation by formulating a method for it to be associated with the stakeholders (Ayuso, Rodri'guez, García-Castro \& Ariño, 2011). Tourais and Videira (2019) stated that close cooperation between organisation and stakeholders is essential as it is the contributor to organisational sustainability transitions.

There are 2 guiding principles highlighted by Foxon and Pearson (2008), namely (1) the stimulation of an event of a property innovation policy regime, the integration of environmental and innovation policy regimes, (2) the implementation of system thinking, which involves the quality and general interactions between political procedures and innovation systems to develop sustainability transitions. Furthermore, Garay, Font and Corrons (2018) posited managers are motivated by the cognitive mechanisms to make an introduction to sustainable practices in businesses. It was found by Teixeira, Andreassi, Köseoglu and Okumus (2019) that a low number of resources is accessed by entrepreneurs during the start-up phase. Accordingly, only friends and family play a role as the primary moral support. Wikhamn (2019) elaborated that sustainable human resource (HR) practices in the organisation influence the association between customer's satisfaction and sustainable innovation.

\subsection{Creativity}

Creativity is important for day-to-day marketing decision making and the judgement of creative marketing work, such as campaign advertisement and other forms of integrated marketing communications (Swaminathan, 2019). There have been various definitions of creativity. Among all the definitions, two concepts regarding suitability and newness are highlighted (Fadaee \& Alzahrh, 2014). Meanwhile, Knight and Harvey (2015) and Pick et al. (2015) argued that a creative company was identified in most studies as a company with an engagement in the creative industry (as cited in Bérubé and Demers 2019). Amabile (1988) stated that the creative activities of individuals within the organisation and organisational structure are the crucial elements in promoting innovation. Furthermore, creativity would emerge when a new solution is created to solve an issue. There are two elements to this definition, namely the solution to an issue and an innovative and emerging solution to the individual who solves the issue (Hosseini, 2001). Despite the presence of creativity in hospitality/tourist attractions, high creativity 
level could be seen in certain activities (Camarero et al., 2018). In other words, creativity in hospitality enterprises new ideas and approaches to be present, which is essential for new opportunities to develop for the creation of business value.

There are two main obstacles for creativity in idea development and application of innovation, namely staff refusal of change and the rejection of new innovations among customers (Lee, Hallak \& Sardeshmukh, 2019). Ibrahim, Che, Sharifah, Mohd and Owolabi (2015) stated that when innovation is harnessed by obtaining understanding and creativity, it is important for the realities of innovation to be thought upon as it occurs in the recent times $(\mathrm{OECD}, 2015)$. This does not result in different ranges of production scale. Instead, it contributes to additional capabilities in managing various organisational tasks which assist in making efficient offerings. In respect to this, sustainable innovation is a mechanism which aids hospitality enterprises to gain creative skills and innovative competitive advantages over its competitors within a rapidly changing business environment.

\subsection{Value Creation (Entrepreneurship)}

The creation of value for customers involves the creation of products and provision of services which are constantly beneficial for the customers. In the recent economy, it is usually based on the innovation of process and product the comprehension regarding customers' distinctive needs with ever-increasing accuracy and speed. However, the innovation and provision of exceptional service are possible for organisations, provided if they utilise the employees' imagination, energy, and commitment (O'Malley, 1989). Although influential organisations do not take part in the evolved economic system, identifying opportunities and the creation of value for nation-building would be challenging for entrepreneurs. Although it is clear that this issue is not initially effective for the economy (LSUS Shreveport, 2017), it does specify the economic system the smaller and developing groups. With this, entrepreneurs have a chance to experience new business ideas and fashions.

With this chance, individuals in revolutionary entrepreneurial enterprise perceive an increase in the necessity of stability in economies which are developing. It is stated by many that the success of innovative marketers is the factor of the continuation of advanced economies. Nimfa (2015) added that an entrepreneurial attitude has a significant influence on graduates' desire for self-employment and business start-up. LSUS Shreveport (2017) highlighted that imagination is crucial to start a business. This does not regard the emergence of interesting new products or services or the use of modern goal-marketplace engagement and analysis. However, the responsibilities of a small enterprise proprietor, singular entrepreneur, or any particular employee are not limited to imagination alone. Besides, the most effective hospitality organisations incorporate creativity and promote sustainable innovation. Therefore, value creation in hospitality enterprises is necessary for the current business environment. With value creation, quality services could be offered to customers and the public, and new chances could be created for the sustainable growth of the business.

\subsection{Sustainable Innovation and Customers Satisfaction for Value creation}

Innovation is the benefits of current thoughts stemmed from creativity. There is a belief that it is possible for innovation to be a new carrier or method of performing certain acts, or a brand new product. Jones, Hillier and Comfort (2016) highlighted that rather than the ongoing commitment to sustainability, sustainability in the hospitality industry could be defined around the necessity of business. Furthermore, the comprehension of the association between sustainability and customers' satisfaction is essential to encourage sustainable development (Gerdt, Wagner \& Schewe, 2019). Moreover, Ayuso et al. (2011) the organisation's sustainable innovation orientation is the outcome of the knowledge originated from engagement with external and internal stakeholders. However, it is crucial for the organisation to manage the knowledge internally so that new ideas could be formed for innovation. Collins and Reutzel (2017) also suggested that top manager perceptions of environmental munificence, firm resource management capabilities, and organizational controls are positively related to firm investment in innovation.

An improved comprehension was presented by Halim et al. (2014) on the particular elements which enhance the human capital and innovation culture, which are important for the creation of the venture. Martin-Rios and Ciobanu (2019) elaborated that hotels sales turnover has a positive association only with complex innovation methods which focus on technological and non-technological innovations. Besides, Horng, Liu, Chou, Tsai \& Hu (2018) implied the direct and indirect impacts of innovation diffusion on organisational factors and the dimensions of sustainable innovation. Furthermore, sustainable innovation appeared as the most crucial element when analytic network process analysis was involved. Gerdt et al. (2019) added that the association between sustainability orientation and customer satisfaction was moderated by star classification. According to Halim, Ahmad, Ramayah, Hanifah \& Taghizadeh (2015), the significance of innovation culture via organisational learning in business activities was emphasised by SME entrepreneurs. Although innovation culture was regarded by some entrepreneurs as something which is challenging to foster, it functions as a key trend which determines their innovative performance in the aspect of developing new knowledge, skills, and ideas. Therefore, it could be seen from the explanation that the relationship between sustainable innovation and customers' satisfaction was mixed 
and inconclusive. Accordingly, the following hypothesis was developed:

H1: The association between sustainable innovation and customers' satisfaction in the hospitality enterprises in Jos Metropolis is significant.

\subsection{Creativity and Competitiveness for Value Creation}

In an attempt to explain the link between creativity and competitiveness for value creation, Hassi (2019) found that leaders' empowerment in the implementation of new management processes, practices, or structures is shaped by the climate for creativity dimensions of flexibility to transformation, sufficient resources for innovation, and employee's creativity recognition. Furthermore, Cyril, Dakung and Goyit (2018) found a significant and positive prediction by innovative service delivery on the competitive advantage of Nigeria's small and medium enterprises. Camarero, Garrido and Vicente (2019) stated that although creativity orientation posed a positive effect on the operating performance of museums, a curvilinear impact could be seen on the funding performance. Ibrahim et al. (2015) highlighted the prominence of creative effects, which are obtained through learning to prove revolutionary strategies. Competitiveness appears to be known through the methods of proficiency in managing various knowhow assets of the business enterprise. According to Harvard's Michael Porter, "the only meaningful concept of competitiveness at the national level is productivity" (as cited in Atkinson, 2013). Accordingly, Mohsin, Halim and Ahmad (2015) added that there is an agreement that the traits of the entrepreneur are the influencing factors of the engagement of competitive intelligence.

Eskandari, Miri, Gholami, and Nia (2015) highlighted that the competition between competitors is known as the most crucial determinant for the industry, which functions as opportunity creators for the organisation. It also shows a more superior performance compared to the competitors in the competition scene. Andrades and Dimanche (2019) suggested that Russian professionals enhance their competence in terms of research and marketing skills, and sustainable management in hospitality and tourism management. In general, the competitiveness clusters initiative in Croatia did not fulfil the members' standards (Anić, Corrocher, Morrison \& Aralica, 2019). It could be said from this discussion that ambiguities are present in the relationship between creativity and competitiveness for value creation. Therefore, the following hypothesis was formulated:

$\mathrm{H} 2$ : The association between creativity and competitiveness for value creation in the hospitality enterprises in Jos Metropolis is significant.

\subsection{Utilisation of Technology and Value Creation}

The rapid ICT development for the tourism and hospitality industry promotes the adaptation to new technologies by hotels around the global (Quarshie \& Amenumey, 2018). It is essential for hotels to undergo a transformation so that customers' varying demands in terms of experience and age are fulfilled. With this transformation, hotels would be able to surpass industry disruptors and traditional competitors within a rapidly evolving competitive environment (Lam \& Law, 2019). According to Camarero et al., (2018) there the adaptation to the audience and new technology use are positively used for visitor engagement.

Presenza, Petruzzelli, and Sheehan (2019) discovered that the value of innovation could be enhanced through the identification and combination of tangible and intangible characteristics of tradition from different points of time. This enhancement could occur especially with the perception that the authenticity of guest experience could be improved. Furthermore, Kornova and Loginova (2019) emphasised that a specific focus must be placed on technology use which fulfils the needs of customers in hospitality enterprises. These enterprises represent new generations. It was concluded in the evidence from Quarshie and Amenumey's (2018) works that promoting ICT use in the hospitality industry was crucial in Ghana and the Central Region in general. Nieves and Osorio (2019) added that the association between management innovation and IT use was positive and direct. However, the association between knowledge integration capability and organisational knowledge was indirect. Moreover, Hong \& Wang (2011) showed that loyalty could be influenced by satisfaction with the marketer's information technology system (as cited in Taillon \& Huhmann, 2017). Internet development and technological innovation posed a revolutionary effect on hotel industry development (Ruan \& $\mathrm{Li}, 2019$ ). It could be seen from the explanation above that there has been an insufficient discussion on the association of technology used for the creation of value in hospitality enterprises. Accordingly, the following hypothesis was stated:

H3: The association between technology use and the creation of value in hospitality enterprises in Jos Metropolis is significant.

\subsection{RESEARCH METHOD}

A descriptive survey research design was adopted, which was appropriate as the characteristics of individuals' needs as a solution to the issue were not the only focus of this study. 150 managers in Jos Metropolis among the selected hospitality accommodation owners were chosen as the overall population. The study's sample size consisted of 108 individuals, who were determined using the statistical formula by Morgan and Krejcie (1970). This study was conducted on the registered members of the Hospitality and Tourism Management Association of 
Nigeria (HATMAN). Furthermore, the enterprises were carefully chosen due to insufficient value creation for customers' patronage, creativity, sustainable innovation, and degree of service delivery in the marketplace. Data collection was performed at the State Ministry of Culture and Tourism in Plateau State, with a quantitative approach being the primary method applied in this phase.

According to Bodmin (2004) generalisation of the results to the overall population is possible in quantitative research through a careful acquirement of the sample. In this study, primary data was obtained from respondents through the survey questionnaire, which consisted of two parts. The first part focused on personal information (demographic questions about age, education, and the owner-manager years of experience), while the second part focused on primary research questions on the dependent and independent variables. Accordingly, 108 copies of questionnaire were distributed to the owner-managers of every selected hospitality enterprise. Five (5) point Likert scale was used to rate all questionnaire items, with the scale ranging from $1=$ strongly disagree, $2=$ disagree, $3=$ neutral, $4=$ agree, to $5=$ strongly agree. The Ordinary Least Square (OLS) regression method was utilised to test the formulated hypotheses. With this, the linear relationship between the dependent and independent variables was determined. In fact, the OLS is the most precise (efficient) unbiased estimation technique, which is frequently used to estimate the parameters of regression models with the assistance of statistical package for social science (SPSS) software.

\section{Model Specifications}

Following are the model specifications for this study:

$C S=\beta_{0}+\beta_{1} S I N V+\mu_{t}-\cdots-\cdots-1$

$C O M=\beta_{0}+\beta_{2} C R S+\mu_{t}-\cdots--2$

$V C=\beta_{0}+\beta_{3} U T+\mu_{t}-\cdots-\cdots--3$

Where;

CS = Consumer's satisfaction

SINV = Sustainable innovation

COM = Competitiveness

CRS = Creative skills

$V C=$ Value creation

UT = Utilisation of technology

$\beta_{0} \quad=$ The intercept

$\beta_{1,} \beta_{2,} \beta_{3}=$ Coefficient of hospitality structure, lighting, and room temperature

$\mu_{t} \quad=$ Error term

\section{FINDINGS AND DISCUSSION}

\subsection{Results}

108 survey instruments were distributed to the target respondents (selected owner-managers of hospitality enterprises) during office hours. The distribution was made through face-to-face interactions, email address, and phone calls. The data in 90 of the questionnaire copies were returned in hardcopy and digital forms. Overall, the data represented 97.2 per cent of the issued questionnaire, while the other 18 copies which were not returned were represented by 2.8 per cent. Out of the questionnaires which were distributed, $97 \%$ responses were retrieved for presentation through descriptive statistics, such as frequency tables and simple percentages.

Based on Table 4.1, (refer to appendix) it could be seen from the respondents' age distribution that 66 of them, who were represented by 61.11 per cent, aged 31 years old and above. Meanwhile, 22 of them, who were represented by 20.37 per cent, aged from 26 to 30 years old. 15 of them, who were represented by 13.89 , aged from 21 to 25 years old. On the other hand, 5 of them, who were represented by 4.63 per cent aged from 15 to 20 years old. This indicated that most owner-managers who owned hospitality enterprises aged 31 years old and above.

Based on Table 4.2, 45 owner-managers, who consisted of HND / B.Sc holders were represented by 41.66 per cent. The other 30 owners were managers who also held a Master, and they were represented by 27.78 per cent. Meanwhile, 18 owner-managers were represented by 16.67 present, and they were placed under the "others" category. This left the rest of the 15 owner-managers who were represented by 13.89 per cent, and they were Mhil $/ \mathrm{PhD}$ holders. Overall, it could be seen that most owner-managers in the hospitality enterprises were HND/Bachelor holders.

Based on Table 4.3, it was shown that 28 respondents, who were represented by 25.93 per cent, had served for 1-5 years. They also represented the majority of the owner-managers in the enterprises. 25 respondents, who were represented by 23.15 per cent had been in hospitality enterprises for 11-15 years. Meanwhile, 24 respondents, who were represented by 22.23 per cent had been involved in business for 21 years and above. 21 respondents who were represented by 19.44 per cent had been in the hospitality enterprise business for 16 to 20 years. This left 10 respondents who were represented by 9.25 per cent. They had served for 6 to 10 years. As the owner-managers in the business had less than five years of experience in their service, it could be implied that they understood that 
innovation and creativity skills would create value to their enterprise's operation.

Based on Table 4.4, it was shown that 38 respondents, who were represented by 35.19 per cent answered with "strongly disagree". 29 respondents, who were represented by 26.85 per cent answered with "disagree". Meanwhile, 16 respondents who were represented by 14.81 per cent answered with "agree". 13 respondents, who were represented by 12.04 per cent answered with "strongly agree". This left 12 respondents who chose to be neutral. They were represented by 11.11 per cent. As the majority of the respondents was those answered with "strongly disagree" and "disagree", it could be seen that the process of creativity and work role innovation has not improved in terms of value creation for business opportunities in hospitality enterprises.

Based on Table 4.5, 53 respondents, who were the majority of them, were represented by 49.07 per cent. They answered with "strongly agree". This was followed by 24 respondents who were represented by 22.22 per cent, and they answered with "strongly disagree". Meanwhile, 18 respondents, who were represented by 16.68 per cent answered with "agree". 9 respondents who were represented by 8.33 per cent answered with "disagree". This left with 4 respondents who answered with "neutral", and they were represented by 3.70 per cent. It was indicated that the respondents successfully went through multiple innovation processes at all different development phases for quality service delivery in hospitality enterprises.

Based on Table 4.6, 31 respondents, who were represented by 28.70 per cent answered with "strongly agree". Meanwhile, 29 respondents, who were represented by 26.85 per cent answered with "agree". 19 respondents, who were represented by 17.59 per cent answered with "disagree", while 16 respondents who were represented by 14.82 per cent answered with "neutral". This left 13 respondents, who were represented by 12.04 per cent, answered with "strongly disagree". As most of the respondents answered with "strongly agree" and "agree", it was indicated that in idea development and implementation, various stages in the motivation process were influenced by various entrepreneurial attributes.

Based on Table 4.7, 40 respondents, who were represented by 37.04 per cent answered with "strongly agree". Meanwhile, 22 respondents, who were presented by 20.37 per cent answered with "agree". 21 respondents, who were represented by 19.44 per cent answered with "disagree", while 20 respondents who were represented by 18.52 per cent answered with "strongly disagree". This left 5 respondents, who answered with "neutral". They were presented by 4.63 per cent. With "strongly agree" and "agree" being the majority of the answers, it could be seen that creativity and innovation training interventions were effective in building business opportunities for hospitality enterprises.

Based on Table 4.8, 46 respondents, who were represented by 42.59 per cent answered with "disagree". Meanwhile, 26 respondents, who were represented by 24.07 per cent answered with "strongly disagree". 20 respondents who were represented by 18.52 per cent answered with "agree", while 9 respondents who were represented by 8.34 per cent answered with "strongly disagree". This left 7 respondents who answered with neutral, and they were represented by 6.48 per cent. As "disagree" and "strongly disagree" were the majority of the answers, it could be seen that the created value in the marketplace was not the possessed mechanisms which performed the most effective switch between the requests of competing tasks in routine task management in the hospitality enterprises.

Based on Table 4.9, 54 respondents who were represented by 50 per cent answered with "strongly agree". Meanwhile, 30 respondents who were represented by 27.77 per cent answered with "agree". 10 respondents who were represented by 9.26 per cent answered with "strongly disagree", while 9 respondents who were represented by 8.34 per cent answered with "neutral". This left 5 respondents who answered with "disagree". They were represented by 4.63 per cent. As "strongly agree" and "agree" were the majority of the answers, it was indicated that past experiences were important during innovation. The same went to their effects for value creation in a marketplace for hospitality enterprise in the future.

Based on Table 4.10, 47 respondents who were represented by 43.52 per cent answered with "agree", while 35 respondents who were represented by 32.41 per cent answered with "disagree". 15 respondents who were represented by 13.89 per cent answered with "strongly disagree". 7 respondents who were represented by 6.48 per cent answered with "neutral", leaving 4 respondents who answered with "disagree". They were represented by 3.70 per cent. As "agree" and "strongly agree" were chosen by most of the respondents, it was implied that perceived innovative behaviour or counter-productive behaviour were the keys to hospitality enterprises' survival.

\subsection{Test of Hypotheses}

In accordance with statistical research, the three hypotheses created in this research were approached with the aid of t-statistics present in the regression results. The degree of significance for the research was $5 \%$ for a two-tailed test. It was also recommended that the null hypothesis should be used if the critical t-value of \pm 1.96 was higher than the estimated value from this research analysis. Otherwise, the value would be rejected.

\subsubsection{Hypothesis One}

H1: The association between innovation and customer's satisfaction in hospitality enterprises in Jos Metropolis is significant. 
Table 4.11: Regression results of sustainable innovation and customer's satisfaction in hospitality enterprises in Jos Metropolis

$$
\text { Regression analyses of sustainable innovation on variables of outcome }
$$

Dependent Variable: Consumer's satisfaction

$$
R^{2}=0.167 ; F=47.443 ; \text { Sig }=0.0000
$$

\begin{tabular}{lcccc}
\hline Independent Variable & Beta & t-value & Pearson Correlation(r) & Probability value \\
Sustainable innovation & 0.645 & 6.88 & 0.408 & 0.0000 \\
\hline
\end{tabular}

Based on the regression result in Table 4.11, the t-value for sustainable innovation amounted to 6.88 , which was higher than the 1.96 , which was the critical value. Therefore, the first hypothesis $\left(\mathrm{H}_{1}\right)$ of this study was accepted. It could be concluded that there was a significant association between customer's satisfaction and sustainable innovation in hospitality enterprises in Jos Metropolis.

Based on Table 4.11, ' $\mathrm{R}$ ' confirmed the association between the dependent variable (customer satisfaction) and independent variable (sustainable innovation). It was found that sustainable innovation had a significant association with the customer's satisfaction, as indicated by the model. Adjusted $\mathrm{R}^{2}(.163)$ implied that customer's satisfaction with hospitality enterprises was represented with 16.3 per cent. Generally, their satisfaction was influenced by sustainable innovation. Meanwhile, the remaining $83.7 \%$ was due to other factors not identified by the model.

Based on Table 4.12, sustainable innovation had a significant association with customers' satisfaction in the hospitality enterprises with 5\% significance rate. At 5\% significance level, F- calculated amounted to 47.443, while F- tabulated had a total sum of squares of 131.907. This indicated that if the owner-managers of hospitality enterprises were adapted to sustainable innovation in the management of their operations, customers' satisfaction and needs would be fulfilled. As a result, it would contribute to high business opportunities in enterprises.

4.2.2 Hypothesis Two

$\mathrm{H} 2$ :The association between creativity skills and enhanced competitiveness in hospitality enterprises in Jos Metropolis is high.

Table 4.14: The regression results of creativity skills and competitiveness

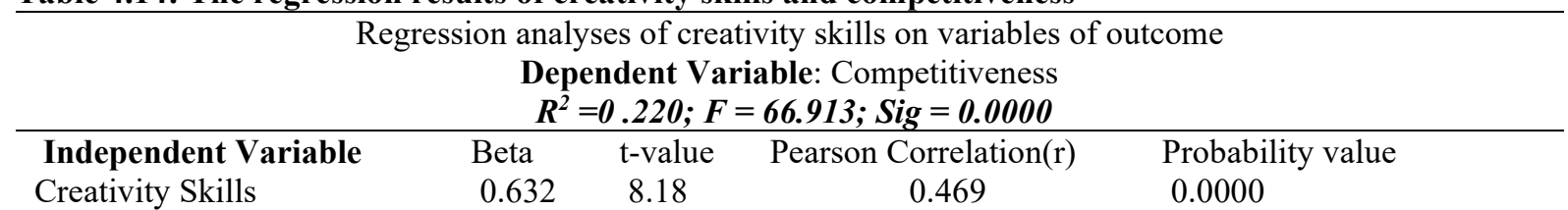

Based on Table 4.14, the calculated t-value for creativity skills amounted to 8.18, while it was provided that the critical value amounted to 1.96 under $95 \%$ of confidence rate. With the calculated $t$-value being higher than the tabulated value $(8.18>1.96)$, the second hypothesis $\left(\mathrm{H}_{2}\right)$ was accepted. It was then concluded that creativity skills were highly associated with enhanced competitiveness in hospitality enterprises in Jos Metropolis.

Based on Table 4.14, ' $\mathrm{R}$ ' confirmed the association between the dependent variable (competitiveness) and independent variables (creativity skills). As it was found that a significant relationship was present between creativity skills and competitiveness, hypothesis (H2) was then accepted. Adjusted $\mathrm{R}^{2}(0.217)$, indicated that the creative skills in the enhanced competitiveness in hospitality enterprises in Jos Metropolis were rated as $21.7 \%$. The remaining $78.3 \%$ was due to other factors not identified in this study.

Based on Table 4.15, a strong association was present between creativity skills and competitiveness in the hospitality enterprises, with a 5\% significance level. At this significance level, F -calculated amounted to 66.913, while F- tabulated had a total sum of squares of 40.304. This also implied that the management of hospitality enterprises in Jos Metropolis required the improvement in creativity skill. With this improvement, enterprises would gain a competitive advantage in the business environment. Otherwise, they would not easily survive in the challenging prevalent economy of the current times.

\subsubsection{Hypothesis Three}

$\mathrm{H}_{3}$ :The association between utilisation of technology and value creation for business opportunities in hospitality/tourism enterprises in Jos Metropolis is high.

Table 4.17: Regression results of utilisation of technology and value creation

\section{Regression analyses of the utilisation of technology on outcome variables}

Dependent Variable: Value Creation

$R^{2}=0.156 ; F=43.895 ;$ Sig $=0.000$

\begin{tabular}{lcccc} 
Independent Variable & Beta & t-value & Pearson Correlation(r) & Probability value \\
Utilisation of technology & 0.294 & 6.62 & 0.395 & 0.000 \\
\hline
\end{tabular}

Based on the regression result in Table 4.17, the calculated t-value for utilisation of technology amounted to 6.62, while the tabulated value amounted to 1.96. As the estimated $t$-value was higher than the critical $t$-value 
$(6.62>1.96)$, it belonged to the rejection region. Therefore, hypothesis $(\mathrm{H} 3)$ was rejected. It was concluded that utilisation of technology had no strong association with value creation for business opportunities in hospitality enterprises in Jos Metropolis.

Based on Table 4.17, ' $\mathrm{R}$ ' confirmed the association between the dependent variable (value creation) and independent variable (utilisation of technology). It was shown that there was no significant relationship between the utilisation of technology and value creation. Therefore, hypothesis (H3) was not supported. The adjusted $\mathrm{R}^{2}$ $(0.156)$ indicated the creativity skill in value creation for business opportunities in hospitality/tourism enterprises in Jos Metropolis was rated to $21.7 \%$. The remaining $78.3 \%$ was due to other factors not identified in this study.

Based on Table 4.18, there was no strong association between the utilisation of technology and value creation for business opportunities in the hospitality enterprises, with $5 \%$ significance degree. At this degree, $\mathrm{F}$-calculated amounted to 43.895 , while F- tabulated amounted to 0.000 , despite the value of F-calculated as higher than Ftabulated with a total sum of squares of 40.304. This implied that the utilisation of technology was highly important in hospitality/tourism enterprises. Therefore, besides the owner-managers being the key to the objectives behind proper utilisation of technology, improved value creation for business opportunities would emerge. With this improvement, profit could be maximised in the long run so that both administrative and overhead/running costs would be operated at full capacity.

\section{CONCLUSIONS AND RECOMMENDATIONS}

\subsection{Conclusions}

The influence of innovation and creativity on value creation of hospitality enterprises Jos Metropolis was examined in this study. A survey research design was implemented, where the applications of scientific methods were involved through the analysis and investigation of the source material. This was followed by data interpretation, generalisation, and prediction. This study was conducted on the registered members of the Hospitality and Tourism Management Association of Nigeria (HATMAN). Furthermore, the owners-managers in hospitality enterprises were carefully selected due to inadequate innovation and creativity for value creation to customers' patronage and level of service delivery in the marketplace. The formulated hypotheses were tested using simple linear regressions. As a result, it was found that a significant relationship was present between all the variables involved, namely innovation and customers' satisfaction, creativity skills and competitiveness, utilisation of technology, and value creation. Accordingly, it was implied that innovation and creativity within well-run enterprises are constantly known as a definite method towards success and value creation for business opportunities in hospitality enterprises in Jos Metropolis. Additionally, the increase in the organisation's productivity was due to creativity, the stimulation of innovation, and the discovery of new and unknown territories. Besides, cost-effective business solutions could be achieved if employees are encouraged to think beyond. This outcome is also achievable if resources and time are given for them to delve into new areas in the acquirement of innovative ideas.

\subsection{Recommendations}

According to the findings, this study arrived at several recommendations:

i.In order to create value, owners-managers in hospitality enterprises should improve their level of sustainable innovation for the improvement in service delivery. It is also recommended that they focus on customers' needs and satisfaction. This initiative would assist them in generating revenue, high return on investment, increasing profits margin, and obtaining large market share. With the realisation of these outcomes, the government would obtain support in wealth creation, employment generation, and large economic scale which could increase productivity.

ii.It is important for the government and owner-managers to encourage expertise, creative skills, and competitiveness in business management practices for value creation in the hospitality/tourism enterprises. These traits would contribute to the improvement in policy-making decisions, which would be in accordance with the best global practice.

iii. The cooperation between owner-managers and the government is imperative. Furthermore, cost-effective utilisation of technology is essential to increase mutual benefits for parties, promote efficient utilisation of resources, and encourage value creation for improved business opportunities in hospitality/tourism enterprises.

\section{REFERENCES}

Amabile, T. M. (1998). How to kill creativity (Vol. 87). Boston, MA: Harvard Business School Publishing.

Anderson, N., Potočnik, K. \& Zhou, J. (2014). Innovation and creativity in organizations: A state-of-the-science review, prospective commentary, and guiding framework. Journal of management, 40(5), 1297-1333.

Andrades, L. \& Dimanche, F. (2019). "Destination competitiveness in Russia: tourism professionals' skills and competences", International Journal of Contemporary Hospitality Management, 31(2), 910-930.

Anić, I.-D., Corrocher, N., Morrison, A. \& Aralica, Z. (2019). The development of competitiveness clusters in Croatia: a survey-based analysis. European Planning Studies, 1.21. 
Atkinson, D. R. (2013). Competitiveness innovation and productivity: cleaning up the confusion. The Information Technology and Innovation Foundation (ITIF), United States, 1-7.

Ayuso, S., Rodríguez, A. M., García-Castro, R. \& Ariño, A. M. (2011). Does stakeholder engagement promote sustainable innovation orientation? Industrial Management \& Data Systems, 111(9), 1399-1417.

Basargekar, P. \& Rawat, P. (2015). Analysis of divergent backgrounds of social entrepreneurs in India in stimulating social innovations in the field of education. Journal of Asia Entrepreneurship and Sustainability 11(2), 81-114.

Bérubé, J. \& Demers, C. (2019). Creative organizations: when management fosters creative work. Creative Industries Journal, 1-27.

Bocken, N. M. P., Short, S.W., Rana, P. \& Evans, S. (2014). A literature and practice review to develop sustainable business model archetypes. Journal of Cleaner Production 65, 42 - 56.

Bodmin, A. (2004). Statistical inference for social science research. Kampala, Makerere University.

Buckingham, J., Wheldall, K. \& Beam-Wheldall, R. (2013). Why poor children are more likely to become poor readers: The school years. Australian Journal of Education, 53(7), 190-213.

Camarero, C., Garrido, M. J. \& Vicente, E. (2019). Does it pay off for museums to foster creativity? The complementary effect of innovative visitor experiences. Journal of Travel \& Tourism Marketing, 36(2), 144158.

Collins, D. J. \& Reutzel, R. C. (2017). The role of top managers in determining investment in innovation: The case of small and medium-sized enterprises in India. International Small Business Journal: Researching Entrepreneurship, 35(5), 618-638.

Cyril, Y. T., Dakung, R. J. Goyit, M G. (2018). Competitive advantage of small and medium enterprises in Nigeria: The predicting role of innovative service delivery. European Journal of Business and Management, 10(17), 70-79.

Dedeoğlu, B. B., Aydin, S. \& Boğan, E. (2018). The role of the employees in the innovation of the hotel enterprises. Anais Brasileiros de Estudos Turísticos-ABET, 8(3), 85-99.

Dzhandzhugazova E. A., Blinova E. A., Orlova L. N. \& Romanova M. M. (2016) Innovations in hospitality industry. International Journal of Environmental and Science Education, 11(17), 10387-10400.

Dziallas, M. \& Blind, K. (2019). Innovation indicators throughout the innovation process: An extensive literature analysis. Technovation, 80, 3-29.

Eskandari, J. M., Miri, M., Gholami, S. \& Nia, S. R. H. (2015). Factors affecting the competitiveness of the food industry by using porter's five forces model case study in Hamadan Province, IRAN. Journal of Asian Scientific Research, 5(4)185-197.

Fadaee, A. \& Abd, A. H. O. (2014). Explaining the relationship between creativity, innovation and entrepreneurship. International Journal of Economy, Management and Social Sciences, 3(12), 141-277.

Foxon, T. \& Pearson, P. (2008). Overcoming barriers to innovation and diffusion of cleaner technologies: some features of a sustainable innovation policy regime. Journal of Cleaner Production, 16(1), S148-S161.

Garay, L., Font, X. \& Corrons, A. (2018), Sustainability-oriented innovation in tourism: an analysis based on the decomposed theory of planned behaviour. Journal of Travel Research, 58(4), 622-636.

Gerdt, S., Wagner, E. \& Schewe, G. (2019). The relationship between sustainability and customer satisfaction in hospitality: An explorative investigation using eWOM as a data source. Tourism Management, 74, 155-172.

Halim, A. H., Ahmad, H. N., Ramayah, T. \& Hanifah, H. (2014). The growth of innovative performance among SMEs: leveraging on organisational culture and innovative human capital. Journal of Small Business and Entrepreneurship Development, 2(1), 107-125.

Halim, A. H., Ahmad, H. N., Ramayah, T., Hanifah, H. \& Taghizadeh, S. K. (2015). Towards an innovation culture: Enhancing innovative performance of Malaysian SMEs. Academic Journal of Interdisciplinary Studies 4 (2), 85-94.

Hassi, A. (2019). "Empowering leadership and management innovation in the hospitality industry context: The mediating role of climate for creativity". International Journal of Contemporary Hospitality Management, 31(4), 1785-1800.

Hong, S. \& Wang, Y. J. (2011). Invested loyalty: The impact of ubiquitous technology on the current loyalty paradigm and the potential revolution. Journal of Strategic Marketing, 19(2), 187-204.

Horng, J. S., Tsai, C. Y. \& Chung, Y. C. (2018, July). Expert concepts of innovation and entrepreneurship in hotels. In 2018 Global Marketing Conference at Tokyo, 815-817.

Hosseini, A. (2001), "Managing creativity and innovation management" magazine No. 26 approach.

Ibrahim, F. S., Che, N. H., Sharifah, S. S. H., Mohd, B. I. \& Owolabi, S. O. (2015). Innovativeness of creative thinking for value creation. Journal of Education and Social Policy. 2(3), 80-89.

The Katerva Awards (2019). Accelerating the future: About sustainable innovation. Retrieved from https://katerva.net/about/sustainable-innovation

Knight, E. \& Harvey, W. (2015). Managing exploration and exploitation paradoxes in creative organisations. 
Management Decision 53(4), 809-827.

Kornova, G. \& Loginova, E. (2019), Service opportunities in the development of the hospitality services market in terms of the new industrialization. Advances in Social Science, Education and Humanities Research, 240, 496-499.

Krejcie, R. V., \& Morgan, D. W. (1970). Determining sample size for research activities. Educational and Psychological Measurement, 30(3), 607-610.

Lam, C. \& Law, R. (2019). Readiness of upscale and luxury-branded hotels for digital transformation. International Journal of Hospitality Management, 79, 60-69.

Lee, C., Hallak, R. \& Sardeshmukh, S. R. (2019). Creativity and innovation in the restaurant sector: Supply-side processes and barriers to implementation. Tourism Management Perspectives, 31, 54-62.

LSUS Shreveport (2017). Importance of creativity and innovation in entrepreneurship. Retrieved from https://online.lsus.edu/articles/business/creativity-innovation-in-entrepreneurship.aspx.

Martin-Rios, C. \& Ciobanu, T. (2019). Hospitality innovation strategies: An analysis of success factors and challenges. Tourism Management, 70, 218-229.

Melissen, F. \& Sauer, L. (2019). Improving sustainability in the hospitality industry. New York: Routledge, 1-132.

Millar, M. J. C. C., Groth, O. \& Mahon, F. J. (2018). Management innovation in a VUCA world: challenges and recommendations. California Management Review, 61(1) 5-14

Mohsin, A. A., Halim, H. A., \& Ahmad, N. H. (2015). Competitive Intelligence among SMEs: Assessing the role of entrepreneurial attitude orientation on innovation performance. In Innovation, finance, and the economy (pp. 15-22). Springer, Cham.

OECD (2015). Enabling the next production revolution. OECD Publishing.

Nieves, J., \& Osorio, J. (2019) "Using information technology to achieve management innovation. Academia Revista Latinoamericana de Administración, 32(1), 20-39.

Nimfa, T. D. (2015). Entrepreneurship education and business start-up: an impact study on selected tertiary institutions in North Central States, Nigeria. An unpublished MSc Dissertation, Nasarawa State University, Keffi, Nigeria.

O'Malley, P. (1998). Value creation and business success. The System Thinker: Pegasus Communications.

Pick, D., Weber, P., Connell, J. \& Geneste, A. L. (2015). Theorising creative industry management: rebooting the woolly mammoth. Management Decision 53(4), 754-762.

Presenza, A., Messeni Petruzzelli, A. \& Sheehan, L. (2019). Innovation trough tradition in hospitality. The Italian case of Albergo Diffuso. Tourism Management, 72, 192-201.

Quarshie M. J. \& Amenumey, K. E. (2018). Utilisation of information and communication technologies in hotel operations in the central region of Ghana. Journal of Hospitality Management and Tourism, 9(1), 1-13.

Rabino, G., Borri, D. \& Stufano Melone, M. R. (2014). Creativity in architecture: The cognitive process. International Journal for Housing Science, 38(4), 223-229.

Ruan, W. \& Li, Y. (2019). Coupling coordination of internet development, technology innovation and star hotel efficiency. International Journal on Semantic Web and Information Systems (IJSWIS), 15(3), 1-17.

Schaltegger, S. \& Ludeke-Freund, F. (2012). The business case for sustainability concept. Centre for Sustainability Management, Leuphana University of Lueneburg. Retrieved from http://www2.leuphana.de/umanagement/csm/content/nama/downloads/download_publikationen/Schaltegge $r$ Luedeke-Freund Business\%20Case\%20for\%20Sustainability.pdf.[Accessed:23May, 2015$].$

Stubbs, W. \& Cocklin, C. (2008). Conceptualizing a 'sustainability business model'. Organisational. Environment, 21(2), 103-127.

Swaminathan, F. (2019). Methods for Stimulating Creativity and Innovation in Marketing." , Abhigyan 36(4), 20 30.

Taillon, J. B. \& Huhmann, A. B. (2017). Strategic consequences of self-service technology evaluations. Journal of Strategic Marketing, 27(3)1-12.

Teixeira, R. M., Andreassi, T., Köseoglu, M. A. \& Okumus, F. (2019). How do hospitality entrepreneurs use their social networks to access resources? Evidence from the lifecycle of small hospitality enterprises. International Journal of Hospitality Management, 79, 158-167.

Tourais, P. \& Videira, N. (2019). Innovative approaches to organisational sustainability: state- of-the-art and conceptual framework. Social Responsibility and Sustainability, 37-56.

Wikhamn, W. (2019). Innovation, sustainable HRM and customer satisfaction. International Journal of Hospitality Management, 76, 102-110. 
APPENDIX

4. RESULTS

Personal Information

Table 4.1: Age distribution of the owner-manager

\begin{tabular}{lcl}
\hline Variable & Frequency & Per cent $(\%)$ \\
\hline $15-20$ & 5 & 4.63 \\
$21-25$ & 15 & 13.89 \\
$26-30$ & 22 & 20.37 \\
31 and above & 66 & 61.11 \\
Total & 108 & 100 \\
\hline
\end{tabular}

Source: Field Survey, 2019

Table 4.2: Educational qualification as owner-manager

\begin{tabular}{lcl}
\hline Variable & Frequency & Per cent $(\%)$ \\
\hline M.Phil/PhD & 15 & 13.89 \\
Masters & 30 & 27.78 \\
HND/Bachelor & 45 & 41.66 \\
Others & 18 & 16.67 \\
Total & 108 & 100 \\
\hline
\end{tabular}

Source: Field Survey, 2019

Table 4.3: Years of experience as owner-manager in the enterprises

\begin{tabular}{lll}
\hline Variable & Frequency & Per cent $(\%)$ \\
\hline 1-5 Years & 28 & 25.93 \\
6-10 Years & 10 & 9.25 \\
11-15 Years & 25 & 23.15 \\
16-20 Years & 21 & 19.44 \\
21 Years \& Above & 24 & 22.23 \\
Total & 108 & 100 \\
\hline
\end{tabular}

Source: Field Survey, 2019

Table 4.4: Process of creativity and the role of sustainable innovation did not improve value creation for business opportunities in hospitality enterprises.

\begin{tabular}{lcc}
\hline Variable & Frequency & Per cent $(\%)$ \\
\hline Strongly Disagree & 38 & 35.19 \\
Disagree & 29 & 26.85 \\
Neutral & 12 & 11.11 \\
Agree & 16 & 14.81 \\
Strongly Agree & 13 & 12.04 \\
Total & 108 & 100 \\
\hline
\end{tabular}

Source: Field Survey, 2019

Table 4.5: My teams successfully went through multiple innovation processes at all different development phases in the hospitality enterprises for quality service delivery

\begin{tabular}{lcc} 
Variable & Frequency & Per cent $(\%)$ \\
\hline Strongly Disagree & 24 & 22.22 \\
Disagree & 09 & 8.33 \\
Neutral & 04 & 3.70 \\
Agree & 18 & 16.68 \\
Strongly Agree & 53 & 49.07 \\
Total & 108 & 100 \\
\hline
\end{tabular}

Source: Field Survey, 2019 
Table 4.6: Different entrepreneurial attributes impact various stages in the innovation specifically in idea development and application

\begin{tabular}{lcc}
\hline Variable & Frequency & Per cent $(\%)$ \\
\hline Strongly Disagree & 13 & 12.04 \\
Disagree & 19 & 17.59 \\
Neutral & 16 & 14.82 \\
Agree & 29 & 26.85 \\
Strongly Agree & 31 & 28.70 \\
Total & 108 & 100 \\
\hline
\end{tabular}

Source: Field Survey, 2019

Table 4.7: Creativity and sustainable innovation training interventions were effective in building business opportunities for hospitality enterprises.

\begin{tabular}{lcc}
\hline Variable & Frequency & Per cent $(\%)$ \\
\hline Strongly Disagree & 20 & 18.52 \\
Disagree & 21 & 19.44 \\
Neutral & 05 & 4.63 \\
Agree & 22 & 20.37 \\
Strongly Agree & 40 & 37.04 \\
Total & 108 & 100 \\
\hline
\end{tabular}

Source: Field Survey, 2019

Table 4.8: Possessed mechanisms which had the most effective switch between the requests of competing tasks in routine task management in the hospitality enterprises

\begin{tabular}{lcl}
\hline Variable & Frequency & Per cent $(\%)$ \\
\hline Strongly Disagree & 26 & 24.07 \\
Disagree & 46 & 42.59 \\
Neutral & 07 & 6.48 \\
Agree & 20 & 18.52 \\
Strongly Agree & 09 & 8.34 \\
Total & 108 & 100 \\
\hline
\end{tabular}

Source: Field Survey, 2019

Table 4.9: I went through previous experiences of sustainable innovation and their impacts on future value creation in a marketplace for the hospitality enterprise

\begin{tabular}{lcl}
\hline Variable & Frequency & Per cent $(\%)$ \\
\hline Strongly Disagree & 10 & 9.26 \\
Disagree & 05 & 4.63 \\
Neutral & 09 & 8.34 \\
Agree & 30 & 27.77 \\
Strongly Agree & 54 & 50 \\
Total & 108 & 100 \\
\hline
\end{tabular}

Source: Field Survey, 2019

Table 4.10: Perceived innovative behaviour or counter-productive behaviour as the keys to the survival of hospitality enterprises

\begin{tabular}{lcc}
\hline Variable & Frequency & Per cent $(\%)$ \\
\hline Strongly Disagree & 15 & 13.89 \\
Disagree & 04 & 3.70 \\
Neutral & 07 & 6.48 \\
Agree & 47 & 43.52 \\
Strongly Agree & 35 & 32.41 \\
Total & 108 & 100 \\
\hline
\end{tabular}

Source: Field Survey, 2019 


\subsection{Test of Hypotheses}

\subsubsection{Hypothesis One}

H1: The association between sustainable innovation and customer's satisfaction in hospitality enterprises in Jos Metropolis is significant.

Table 4.11: Model summary

\begin{tabular}{|l|l|l|l|l|}
\hline Model & R & R Square & Adjusted R Square & Std. Error of the Estimate \\
\hline 1 & .408 & .167 & .163 & .68098 \\
\hline
\end{tabular}

a. Predictor (constant) sustainable innovation

Table 4.12: Summary of model

\begin{tabular}{|l|l|l|l|l|l|}
\hline Model & Sum of squares & Df & Mean square & F & Sig \\
\hline 1. Regression & 22.001 & 1 & 22.001 & 47.443 & .000 \\
Residual & 109.906 & 237 & .464 & & \\
Total & 131.903 & 238 & & & \\
\hline
\end{tabular}

a. Predictors: (constant) sustainable innovation

b. Dependant variable: customer's satisfaction

Table 4.13 Coefficients

\begin{tabular}{|l|l|l|l|l|l|}
\hline \multirow{2}{*}{ Model } & \multicolumn{2}{|c|}{$\begin{array}{c}\text { Unstandardised } \\
\text { coefficients }\end{array}$} & $\begin{array}{l}\text { Standardised } \\
\text { coefficients }\end{array}$ & \multirow{2}{*}{ T } & Sig. \\
\cline { 2 - 5 } & B & Std. Error & Beta & & .000 \\
\hline $\begin{array}{l}\text { 1. Constant } \\
\text { sustainable } \\
\text { innovation }\end{array}$ & 1.582 & .428 & & 6.888 & .000 \\
\hline
\end{tabular}

Dependent variable (customers' satisfaction)

\subsubsection{Hypothesis Two}

$\mathrm{H} 2$ :The association between creativity skills and enhanced competitiveness in hospitality enterprises in Jos Metropolis is high.

Table 4.14: Model summary

\begin{tabular}{|l|l|l|l|l|}
\hline Model & R & R Square & Adjusted R Square & Std. error of the estimate \\
\hline 1 & .469 & .220 & .217 & .65881 \\
\hline
\end{tabular}

Predictor (constant) creativity skills

Table 4.15: Summary Model

\begin{tabular}{|l|l|l|l|l|l|}
\hline Model & Sum of squares & Df & Mean square & F & Sig \\
\hline 1. Regression & 29.042 & 1 & 29.042 & 66.913 & .000 \\
Residual & 35.800 & 237 & .434 & & \\
Total & 40.304 & 238 & & & \\
\hline
\end{tabular}

a. Predictors: (constant) creativity skill

b. Dependant variable: competitiveness

Table 4.16 Correlation coefficients

\begin{tabular}{|l|l|l|l|l|l|}
\hline \multirow{2}{*}{ Model } & \multicolumn{2}{|c|}{$\begin{array}{c}\text { Unstandardised } \\
\text { coefficients }\end{array}$} & $\begin{array}{l}\text { Standardised } \\
\text { coefficients }\end{array}$ & \multirow{2}{*}{ T } & \multirow{2}{*}{ Sig. } \\
\cline { 2 - 6 } & $\mathbf{B}$ & Std. error & Beta & & .000 \\
\hline 1. Constant & 1.822 & .332 & & 8.180 & .000 \\
$\begin{array}{c}\text { Sustainable } \\
\text { innovation }\end{array}$ & .632 & .077 & .469 & & \\
\hline
\end{tabular}

Dependent variable: competitiveness

4.2.3 Hypothesis Three

H03:The association between utilisation of technology and value creation for business opportunities in hospitality/tourism enterprises in Jos Metropolis is high. 
Table 4.17: Model summary

\begin{tabular}{|l|l|l|l|l|}
\hline Model & R & R Square & Adjusted R Square & Std. error of the estimate \\
\hline 1 & .395 & .156 & .153 & .37879 \\
\hline
\end{tabular}

a. Predictor (constant) utilisation of technology

Table 4.18: Summary model

\begin{tabular}{|l|l|l|l|l|l|}
\hline Model & Sum of squares & Df & Mean square & F & Sig. \\
\hline 1. Regression & 6.298 & 1 & 6.298 & 43.895 & .000 \\
Residual & 34.006 & 237 & .143 & & \\
Total & 40.304 & 238 & & & \\
\hline
\end{tabular}

a. Predictors: (constant) utilisation of technology

b. Dependent variable: value creation

Table 4.19:Coefficients

\begin{tabular}{|l|l|l|l|l|l|}
\hline \multirow{2}{*}{ Model } & \multicolumn{2}{|c|}{$\begin{array}{c}\text { Unstandardised } \\
\text { coefficients }\end{array}$} & $\begin{array}{l}\text { Standardised } \\
\text { coefficients }\end{array}$ & \multirow{2}{*}{ T Sig. } \\
\cline { 2 - 5 } & $\mathbf{B}$ & Std. error & Beta & 14.583 & .000 \\
\hline 1. Constant & 2.781 & .191 & & 6.625 & .000 \\
$\begin{array}{c}\text { Utilisation of } \\
\text { technology }\end{array}$ & .294 & .044 & .395 & & \\
\hline
\end{tabular}

Dependent variable: value creation 